\title{
Inhibitory effects of lupeal acetate of Cortex periplocae on N-nitrosomethylbenzylamine-induced rat esophageal tumorigenesis
}

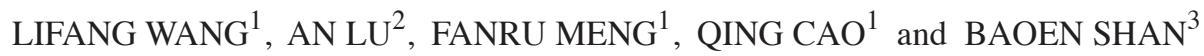 \\ ${ }^{1}$ Laboratory Department, The Second Hospital of Hebei Medical University, Shijiazhuang, Hebei 050000; \\ ${ }^{2}$ Research Center, Hebei Province Center For Disease Prevention and Control, Shijiazhuang, Hebei 050021; \\ ${ }^{3}$ Tumor Research Institute, The Fourth Hospital of Hebei Medical University, \\ Shijiazhuang, Hebei 050017, P.R. China
}

Received February 15, 2012; Accepted May 11, 2012

DOI: $10.3892 / \mathrm{ol} .2012 .717$

\begin{abstract}
Lupeal acetate of Cortex periplocae (CPLA), a triterpene compound extracted from a traditional Chinese herb, has been identified as an inhibitor of cancer cell growth. The objective of the present study was to evaluate the potential mechanisms through which CPLA inhibits N-nitrosomethylbenzylamine (NMBA)-induced rat esophageal tumorigenesis. We treated F344 rats subcutaneously with the esophageal carcinogen NMBA $(0.5 \mathrm{mg} / \mathrm{kg}$ body weight $)$ and intramuscularly with CPLA $(20 \mathrm{mg} / \mathrm{kg}), 3$ times a week for 5 weeks. Rats were then sacrificed at weeks 9,15 or 25 , esophageal tissues were collected and tumor data were recorded. To investigate the mechanisms by which CPLA modulates tumorigenesis in esophagus, we evaluated the protein expression of glycogen synthase kinase- $3 \beta$ (GSK-3 $\beta$ ) and $\beta$-catenin and the gene expression of c-myc. CPLA significantly $(\mathrm{P}<0.05)$ reduced the incidence of esophageal tumors observed at 25 weeks from 93.3\% in NMBA-treated controls to $33.3 \%$ in the NMBAand CPLA-treated rats. CPLA reduced $\beta$-catenin and c-myc expression, but increased GSK-3 $\beta$ expression, in preneoplastic lesions of the esophagus. These results suggest a novel tumorsuppressive role of CPLA through the activation of GSK-3 $\beta$ expression and the inhibition of $\beta$-catenin and c-myc expression. Therefore, CPLA is a potential therapeutic candidate for esophageal squamous cell carcinoma.
\end{abstract}

Correspondence to: Dr Lifang Wang, Laboratory Department, The Second Hospital of Hebei Medical University, 215 Hepingxi Road, Shijiazhuang, Hebei 050000, P.R. China

E-mail: wanglf2h@hotmail.com

Dr Baoen Shan, Tumor Research Institute, The Fourth Hospital of Hebei Medical University, 12 Jiankanglu Road, Shijiazhuang, Hebei 050017, P.R China

E-mail: baoenshan@hotmail.com

Key words: esophageal tumorigenesis, N-nitrosomethylbenzylamine, lupeal acetate of Cortex periplocae, $\beta$-catenin

\section{Introduction}

Esophageal cancer is the third leading cause of gastrointestinal malignancy and the sixth most frequent cause of cancer-related mortality worldwide (1). In China, esophageal cancer is the fourth leading cause of cancer-related mortality, with esophageal squamous cell carcinoma (ESCC) being the major histological subtype (2-4). Statistics indicate the insidious nature of this malignancy and support the importance of developing improved treatments and preventive strategies. Chemoprevention plays an integral role in reducing the incidence of cancer and it is a potentially viable approach to reduce the risk of esophageal cancer in high-risk individuals (5). Herbal and natural products are valuable resources for anticancer drugs (6). Plant-derived active principles, as well as their semi-synthetic and synthetic analogs, have served as one of the major sources for new anticancer drugs $(7,8)$. Several plant-derived anticancer agents, including flavopiridol, acronycine, bruceantin and thalicarpine, are currently being used in US clinical trials (8). Consequently, natural products have been the mainstay of cancer chemotherapy for a number of years (8).

Screening hundreds of traditional Chinese medicines revealed that the extracts of Cortex periplocae (CP) have cancer-preventive properties. CP is the dry root of the traditional Chinese herb Periplocae sepium Bunge, which is referred to as Xiangjiapi in Chinese. It is a traditional type of medicine commonly used to treat inflammation, enhance bone density and muscle mass, and to stimulate the nervous system (9). Itokawa et al found that periplocoside $\mathrm{A}$, which is extracted from $\mathrm{CP}$, markedly inhibited the growth of ascite cancer S180 cells (10). Lupeal acetate $\left(\mathrm{C}_{32} \mathrm{H}_{52} \mathrm{O}_{2} ; \mathrm{MW}, 468\right)$ (Fig. 1), a triterpene compound extracted from $\mathrm{CP}$, is known to significantly inhibit the growth of esophageal cancer, leukemia and breast cancer cells $(11,12)$.

Numerous studies suggest that the activation of the $\mathrm{Wnt} / \beta$-catenin signaling pathway is important in human tumorigenesis (13-16). Therefore, various components of this signaling pathway may serve as rational targets for the development of anticancer drugs. Given the complexity of the Wnt//-catenin 
signaling pathway, it is conceivable that potential cancer drugs may be developed through targeting various nodal points (17). In the Wnt/ $\beta$-catenin signaling pathway, glycogen synthase kinase- $3 \beta$ (GSK-3 $\beta$ ) mediates the degradation of $\beta$-catenin molecules through phosphorylating specific amino acid residues. These residues mark the protein that triggers $\beta$-catenin degradation by the $26 \mathrm{~S}$ proteasome complex $(18,19)$. When the Wnt proteins bind to the Frizzled/low-density lipoprotein receptor-related protein (Fz/LRP) receptor complex, cytoplasmic disheveled (Dvl), a protein downstream of the receptor complex, is phosphorylated and inhibits GSK-3 $\beta$. This process occurs by causing GSK- $3 \beta$ retention at the scaffolding protein axin, which results in the accumulation of non-phosphorylated $\beta$-catenin in the cytoplasm. Non-phosphorylated $\beta$-catenin avoids degradation and translocates into the nucleus in which $\beta$-catenin forms a complex with the transcription factor TCF and induces the transcription of downstream target genes, including c-myc and survivin (20-22). Therefore, GSK-3 $\beta$ is crucial in the regulation of $\mathrm{Wnt} / \beta$-catenin target gene expression through controlling the level of cytoplasmic $\beta$-catenin (23). Overall, an aberrant activation of $\beta$-catenin-dependent signaling is a major contributor in the pathogenesis of ESCC. Therefore, targeting this pathway may have vital implications in controlling the progression of ESCC. The present study was conducted to determine whether pretreatment with lupeal acetate of CP (CPLA) inhibits tumor development in N-nitrosomethylbenzylamine (NMBA)-induced rat esophagus by modulating $\beta$-catenin, GSK-3 $\beta$ and c-myc expression.

\section{Materials and methods}

Animals. A total of 135 male F344 rats (5-6 weeks of age) were purchased from Shanghai Slac Laboratory Animal Co., Ltd. (Shanghai, China). The animals were housed 3 per cage and were kept under standard conditions $\left(20 \pm 2^{\circ} \mathrm{C}, 50 \pm 10 \%\right.$ relative humidity and 12 -h light/dark cycles) in our animal center where food and water were readily available. Hygienic conditions were maintained by cage changes twice a week and routine cleaning of animal rooms. This study was conducted in accordance with the internationally accepted principles for laboratory animal use and the experimental protocols duly approved by the Institutional Ethics Committee of Hebei Medical University.

Chemicals and reagent kits. NMBA was purchased from Nard Co., Ltd. (Osaka, Japan) and CPLA (>85\% purity), identified by Professor Ren, was from New Drug Research and Development Co., Ltd., (North China Pharmaceutical Co., Ltd., Shijiazhuang, China). NMBA was dissolved in saline solution, while CPLA was dissolved in soya oil (Jinghaitang Co., China).

Experimental procedure. Following a 2 week acclimation period to the animal facility, 135 male F344 rats were randomly divided into 5 experimental groups according to their assigned regimens. The study consisted of the following groups: 1,15 rats which subcutaneously (s.c.) received saline $(1 \mathrm{ml} / \mathrm{kg}) ; 2,15$ rats which were intramuscularly (i.m.) injected with soya oil $(1 \mathrm{ml} / \mathrm{kg}) ; 3,15$ rats that were i.m. treated with CPLA $(20 \mathrm{mg} / \mathrm{kg}) ; 4,45$ rats that received NMBA

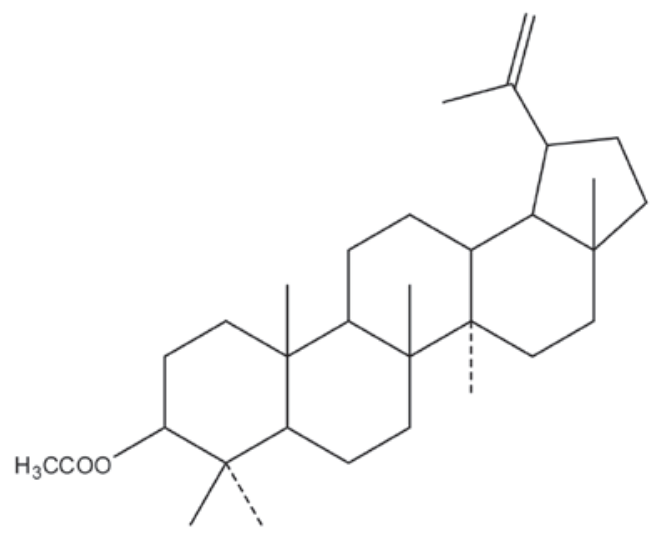

Figure 1. Chemical structure of lupeal acetate extracted from Cortex periplocae.

$(0.5 \mathrm{mg} / \mathrm{kg})$ s.c. and CPLA $(20 \mathrm{mg} / \mathrm{kg})$ i.m.; 5,45 rats treated s.c. with NMBA $(0.5 \mathrm{mg} / \mathrm{kg})$. Groups 1,2 and 3 were negative controls and group 5 was a positive control. The drugs were administered 3 times a week for 5 weeks. At weeks 9 , 15 and 25, 5 rats from groups 1, 2 and 3, and 15 rats from groups 4 and 5 were euthanized using pentobarbital sodium and were subjected to gross necropsy. The esophagus of each rat was excised, opened longitudinally and cut into thirds. Esophagi were then fixed in $10 \%$ phosphate-buffered formalin solution and routinely embedded in paraffin for $\mathrm{H} \& \mathrm{E}$ staining to observe any pathological changes in the tissue. During this time, the $\beta$-catenin and GSK-3 $\beta$ protein expression was detected using western blot analysis and the expression of c-myc mRNA was detected using RT-PCR. The food intake and body weight of each rat were recorded weekly.

Pathological diagnosis. The entire esophagus was removed and longitudinally opened to examine for evidence of gross abnormalities. Samples of esophageal tissue were fixed in $10 \%$ buffered formalin for $24 \mathrm{~h}$ and transferred into $80 \%$ ethanol. The formalin-fixed esophagus was then embedded in paraffin and serial sections $(4 \mu \mathrm{m})$ were mounted onto glass slides for histopathological analyses. Pathological diagnosis of esophageal cancer was determined by a skilled pathologist, who did not know the background of the administered drugs. According to Xiang et al (24), the histopathological features of NMBA-induced tumors in the rat esophagus were classified into papilloma, involving endophytic growth of the epithelium; papilloma with atypia, involving pre-cancerous changes; and carcinoma, involving malignant changes of basal cells, malignant changes of papilloma, carcinoma in situ and early infiltrative carcinoma.

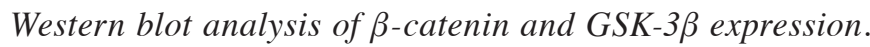
Western blot analysis was performed to determine the $\beta$-catenin and GSK-3 $\beta$ protein expression in the esophageal epithelium. Total protein was isolated from frozen esophageal epithelium by homogenization in ice-cold buffer containing $20 \mathrm{mmol} / \mathrm{l}$ HEPES ( $\mathrm{pH} 7.5$ ), $1.5 \mathrm{mmol} / 1 \mathrm{MgCl}_{2}, 0.1 \mathrm{mmol} / \mathrm{l}$ dithiothreitol, $0.4 \mathrm{~mol} / 1 \mathrm{NaCl}, 20 \%$ glycerol, $0.5 \mathrm{mmol} / 1$ phenylmethylsulfonyl fluoride and $0.5 \mathrm{mmol} / \mathrm{l}$ leupeptin at $4^{\circ} \mathrm{C}$. The insoluble cellular material was removed using microcentrifugation at 

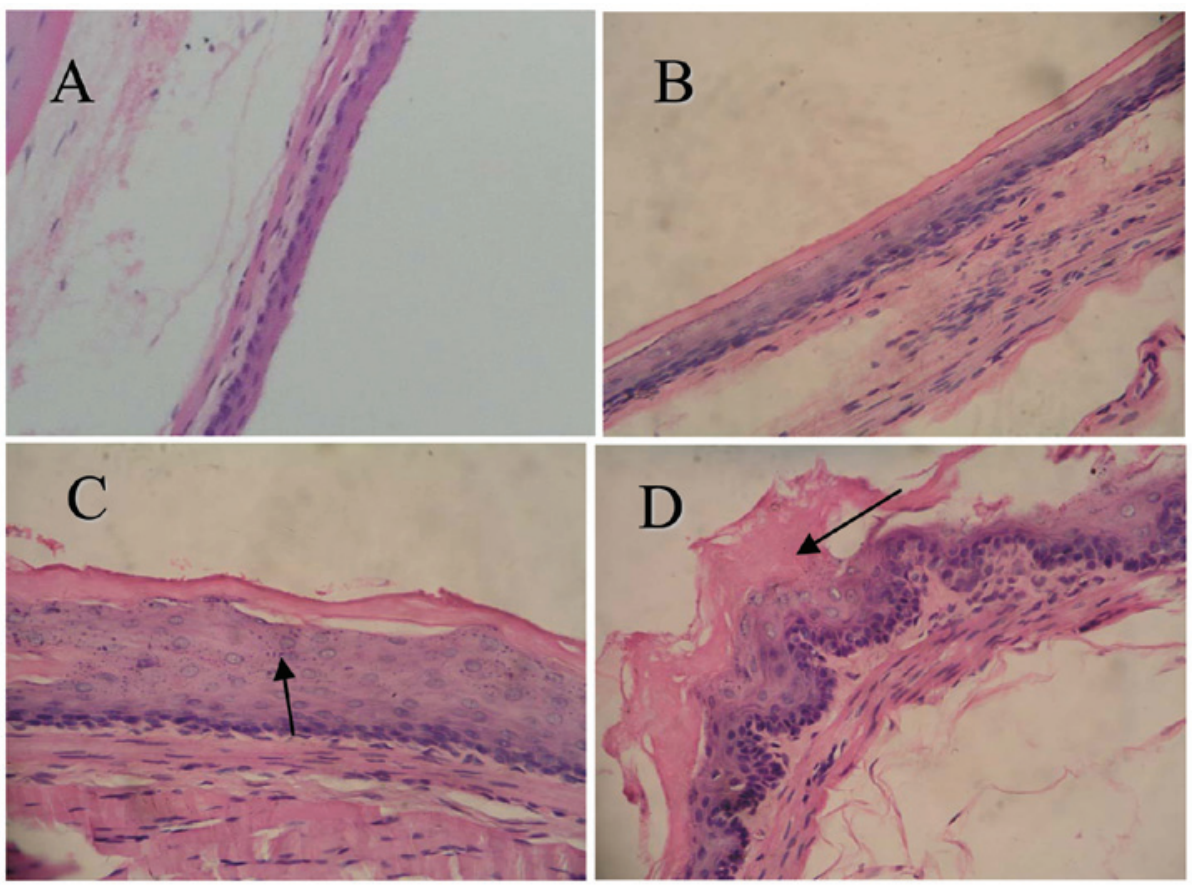

Figure 2. Esophageal tissue sections stained using H\&E staining (magnification, x400). (A) Normal esophageal epithelium composed of an orderly mucosa and basal layer 1-2 cells in thickness. (B) Early focal hyperplasia, indicated by a slight thickening of the basal cells. (C) Extensive hyperplasia, indicated by a heavy thickening of the basal cells (arrow). (D) Low-grade dysplasia, indicated by greater hyperplasia and keratin layers (arrow).

$16,000 \mathrm{rpm}$ for $5 \mathrm{~min}$ and the total protein expression was determined spectrophotometrically. The protein samples were separated using SDS/polyacrylamide gel electrophoresis and transferred to the nitrocellulose membrane for western blot analysis (25).

Semi-quantitative RT-PCR for c-myc expression. Total RNA was extracted from esophageal tissue using TRIzol isolation reagent (Gibco-BRL, Carlsbad, CA, USA), according to the manufacturer's instructions. RNA concentration was measured spectrophotometrically at $260 \mathrm{~nm}$, and the integrity was determined by separating the RNA on $1 \%$ agarose gel and estimating the ratio of $18 \mathrm{~S} / 28 \mathrm{~S}$ rRNA. cDNA was synthesized by the reverse transcription of $2 \mu \mathrm{g}$ of total RNA at $37^{\circ} \mathrm{C}$ for $45 \mathrm{~min}$. First-strand cDNA was then performed using an RT-PCR kit (Sino-American Co., Zhejiang, China) in a $30-\mu 1$ reaction volume, following the manufacturer's instructions.

Following initial denaturation for $5 \mathrm{~min}$ at $95^{\circ} \mathrm{C}$, amplification was conducted for 30 cycles as follows: denaturation at $95^{\circ} \mathrm{C}$ for $30 \mathrm{sec}$, annealing at $55^{\circ} \mathrm{C}$ for $30 \mathrm{sec}$ and extension at $72^{\circ} \mathrm{C}$ for $30 \mathrm{sec}$ and again at $72^{\circ} \mathrm{C}$ for $5 \mathrm{~min}$. PCR products were analyzed using electrophoresis on a $1.5 \%$ agarose gel and images were captured to determine the density of the bands. The relative values of the c-myc and $\beta$-actin bands were calculated in each sample. The sequences of the primers (synthesized at Sangon, Shanghai, China) used in the RT-PCR are shown in Table I.

Statistical analysis. Data were shown as the mean \pm standard deviation (SD). Statistical significance between the groups was determined using the one-way ANOVA and t-test. The $\chi^{2}$ analyses were used to compare the incidences of tumor presentation between the groups. $\mathrm{P}<0.05$ was considered to indicate a statistically significant difference.
Table I. c-myc and $\beta$-actin primer sequences.

\begin{tabular}{llc}
\hline Gene & \multicolumn{1}{c}{ Primer sequence } & $\begin{array}{c}\text { Product } \\
\text { size (bp) }\end{array}$ \\
\hline C-myc & & \\
Sense & 5'CTCCGTCCTATGTTGCG3' & 275 \\
Anti-sense & 5'GCTGGTGCTGTCTTTGC3' & \\
$\beta$-actin & & \\
Sense & 5'CCTCTATGCCAACAGTGC3' & 211 \\
Anti-sense & 5'GTACTCCTGCTTGCTGATCC3' & \\
&
\end{tabular}

\section{Results}

General observations. The mean body weights and food consumption levels in all rats were not significantly different throughout the bioassay (data not shown). No observable gross or histopathological changes occurred in the lungs, liver, kidneys, small intestine or colon of CPLA-treated rats.

Effect of CPLA on preneoplastic lesions in NMBA-treated rat esophagi. To determine the effects of CPLA on microscopic NMBA-induced preneoplastic lesions, we used a histological grading scheme (Fig. 2). At weeks 9 and 15 of the bioassay, $<10$ and $20 \%$ of the esophagi had tumors (papillomas), respectively. However, the tumor responses (incidence and multiplicity) at these time points were too weak to determine whether CPLA treatment produced any inhibitory effects. At the end of the bioassay (week 25), no rats in group 1 (treated with saline), 
Table II. Effects of CPLA on preneoplastic esophageal lesion formation in F344 rats administered with NMBA and euthanized at week 9,15 or 25 .

Pathological changes in esophageal tissue

\begin{tabular}{|c|c|c|c|c|c|c|}
\hline & & & & & & \\
\hline \multirow[b]{2}{*}{ Rat treatment } & \multirow[b]{2}{*}{ Total $\mathrm{n}$} & \multirow{2}{*}{$\frac{\text { Normal }}{n}$} & \multicolumn{2}{|c|}{ Grade I (dysplasia) } & \multicolumn{2}{|c|}{ Grade II (preneoplastic lesion) } \\
\hline & & & $\mathrm{n}$ & Incidence & $\mathrm{n}$ & Incidence $(\%)$ \\
\hline \multicolumn{7}{|l|}{ Week 9 of study } \\
\hline$(-)$ & 5 & 5 & 0 & 0 & 0 & 0 \\
\hline Soya oil & 5 & 5 & 0 & 0 & 0 & 0 \\
\hline NMBA & 15 & 3 & 9 & $9 / 15$ & 3 & $3 / 15(20.0)$ \\
\hline NMBA + CPLA & 15 & $9^{b}$ & 6 & $6 / 15$ & 0 & $0^{\mathrm{a}}$ \\
\hline \multicolumn{7}{|l|}{ Week 15 of study } \\
\hline$(-)$ & 5 & 5 & 0 & 0 & 0 & 0 \\
\hline Soya oil & 5 & 5 & 0 & 0 & 0 & 0 \\
\hline NMBA & 15 & 0 & 8 & $8 / 15$ & 7 & $7 / 15(46.7)$ \\
\hline $\mathrm{NMBA}+\mathrm{CPLA}$ & 15 & $8^{b}$ & 7 & $7 / 15$ & 0 & $0^{\mathrm{a}}$ \\
\hline \multicolumn{7}{|l|}{ Week 25 of study } \\
\hline$(-)$ & 5 & 5 & 0 & 0 & 0 & 0 \\
\hline Soya oil & 5 & 5 & 0 & 0 & 0 & 0 \\
\hline NMBA & 15 & 0 & 1 & $1 / 15$ & 14 & $14 / 15(93.3)$ \\
\hline $\mathrm{NMBA}+\mathrm{CPLA}$ & 15 & 0 & 10 & $10 / 15$ & 5 & $5 / 15(33.3)^{\mathrm{a}}$ \\
\hline
\end{tabular}

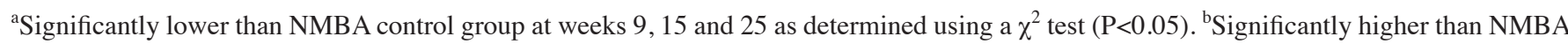
control group at weeks 9 and 15 as determined using a $\chi^{2}$ test $(\mathrm{P}<0.05)$. CPLA, lupeal acetate of Cortex periplocae; NMBA, N-nitrosomethylbenzylamine.

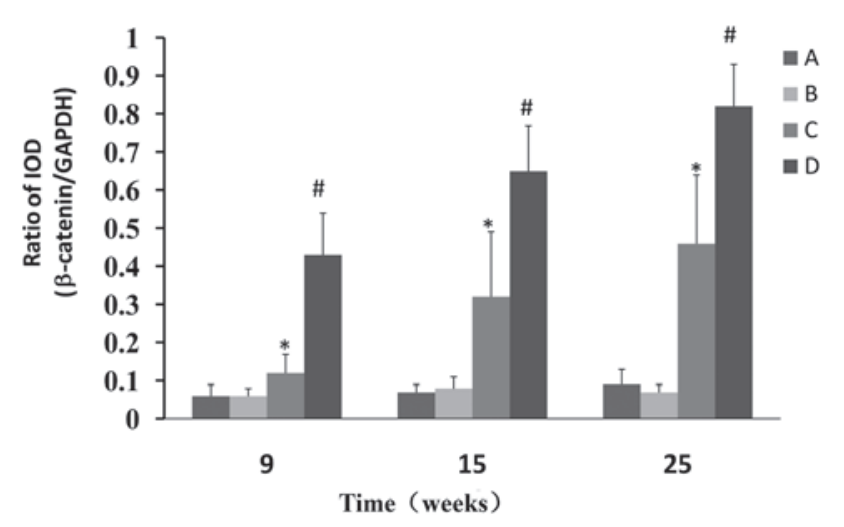

Figure 3. Effects of CPLA on the expression of $\beta$-catenin in rat esophageal NMBA-induced tumorigenesis. Legend: A, normal control; B, soya oil control; C, CPLA and NMBA group; D, NMBA control group. ${ }^{*} \mathrm{P}<0.05$ compared with the NMBA control group; ${ }^{~} \mathrm{P}<0.05$ compared with the normal control group. CPLA, lupeal acetate of Cortex periplocae; NMBA, N-nitrosomethylbenzylamine; IOD, integrated optical density.

group 2 (treated with soya oil) or group 3 (treated with CPLA) developed tumors. In the rats treated with NMBA, CPLA significantly $(\mathrm{P}<0.05)$ reduced the incidence of esophageal tumors from $93.3 \%$ in group 5 (treated with NMBA only), to $33.3 \%$ in group 4 (treated with NMBA and CPLA) (Table II, Fig. 2). Since the esophagi treated with CPLA alone were histologically similar to the vehicle controls, data from group 3 (treated with CPLA alone) are not shown.

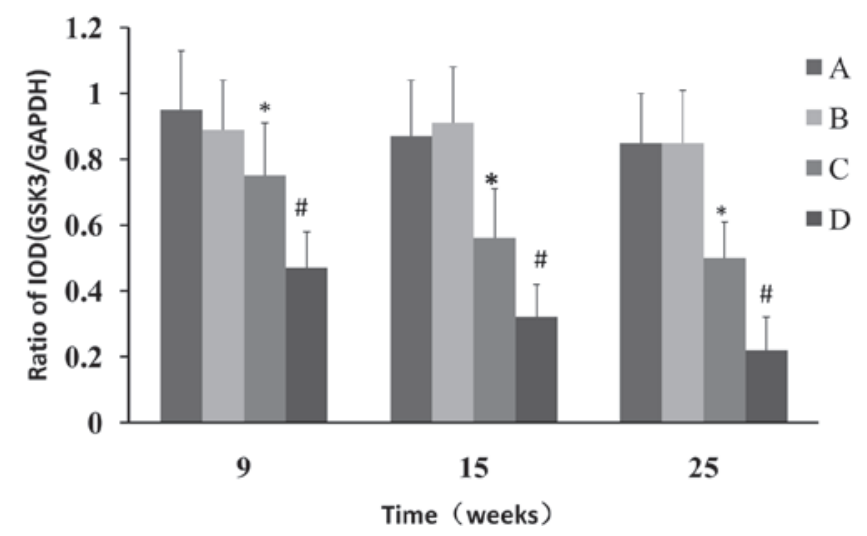

Figure 4. Effects of CPLA on the expression of GSK-3 $\beta$ in rat esophageal tumorigenesis induced with NMBA. Legend: A, normal control; B, soya oil control; C CPLA and NMBA group; D NMBA control group ${ }^{*} \mathrm{P}<0.05$ compared with the NMBA control group; ${ }^{\#} \mathrm{P}<0.05$ compared with the normal control group. CPLA, lupeal acetate of Cortex periplocae; NMBA, $\mathrm{N}$-nitrosomethyl-benzylamine; IOD, integrated optical density.

CPLA inhibits the protein expression of $\beta$-catenin and upregulates the expression of $G S K-3 \beta$. Western blot analysis was used to determine whether CPLA inhibits $\beta$-catenin protein expression in preneoplastic lesions at various times and, if so, whether this inhibition is associated with the modulation of GSK-3 $\beta$. The NMBA-induced overexpression of $\beta$-catenin was significantly $(\mathrm{P}<0.05)$ decreased from 7.2 - to 2.0 -fold, 9.3- to 4.6 fold and 9.1- to 5.1 fold, in rats treated with NMBA 


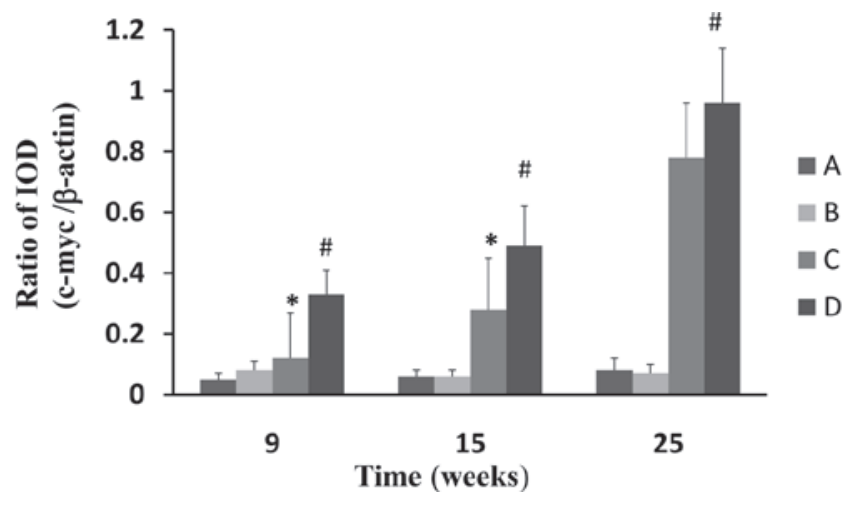

Figure 5. Effects of CPLA on the expression of c-myc in rat esophageal tumorigenesis induced with NMBA. Legend: A, normal control; B, soya oil control; C CPLA and NMBA group; D NMBA control group. ${ }^{*} \mathrm{P}<0.05$ compared with the NMBA control group; ${ }^{\text {}} \mathrm{P}<0.05$ compared with the normal control group. CPLA, lupeal acetate of Cortex periplocae; NMBA, $\mathrm{N}$-nitrosomethyl-benzylamine; IOD, integrated optical density.

and CPLA at 9, 15 and 25 weeks, respectively (Fig. 3). It was also found that CPLA significantly $(\mathrm{P}<0.05)$ upregulates the protein expression of GSK-3 $\beta$ in NMBA-induced rats at weeks 9, 15 and 25 (Fig. 4).

CPLA downregulates mRNA expression of $c-m y c$. Gene expression of c-myc was assessed using RT-PCR with $\beta$-actin as the internal standard. The gene expression of c-myc in the esophageal epithelium of the NMBA-treated rats was significantly $(\mathrm{P}<0.05)$ increased at weeks 9,15 and 25 , in comparison to the normal control (Fig. 5). CPLA treatment significantly $(\mathrm{P}<0.05)$ suppressed the mRNA expression of c-myc at weeks 9 and 15, but not at 25 .

\section{Discussion}

In the present study, the potential inhibitory effects of CPLA, an extract from $\mathrm{CP}$, on NMBA-induced esophageal tumorigenesis in F344 rats, were investigated. We demonstrated that pretreatment with $20 \mathrm{mg} / \mathrm{kg}$ CPLA reduced the tumor incidence rate in NMBA-treated rats compared to NMBA controls. The inhibition of tumor development correlated with reductions in esophageal cell proliferation. Further investigations demonstrated that CPLA acted as a tumor inhibitor by suppressing $\beta$-catenin protein expression and c-myc gene expression, two key proteins of the Wnt signal pathway that have previously been identified to be upregulated in esophageal carcinomas (26). Additionally, CPLA upregulated the expression of GSK-3 $\beta$, a multifaceted kinase in the Wnt signaling pathway (27).

Histopathological data revealed that treating rats with CPLA alone led to few, if any, changes in the esophagus in comparison to the normal control group of rats. By contrast, treatment with NMBA led to basal cell proliferation, cytotoxicity and inflammatory changes in the esophagus. The histological appearance of the esophagus in rats treated with CPLA and NMBA showed a greater degree of normality in comparison to the NMBA control group of rats. Additionally, CPLA reduced the incidence of esophageal tumors from
93.3\% in NMBA controls to $33.3 \%$ in rats treated with NMBA and CPLA. Therefore, our study provided evidence that CPLA significantly suppresses carcinoma development.

Wnt proteins are a large family of secreted glycoproteins that activate signal transduction pathways to control a variety of cell processes, which include determination of cell fate, proliferation, migration and polarity. In normal mature cells, the Wnt pathway regulates normal cellular activities. The majority of $\beta$-catenin within cells binds to E-cadherin on the cell membrane to form a complex-epidermal catenin and cadherin unit (ECCU). Free $\beta$-catenin levels are normally kept low through a phosphorylation event that is mediated by GSK-3, $\alpha$ and $\beta$ isoforms, which target $\beta$-catenin for ubiquitylation and proteasomal degradation. When the Wnt pathway is activated by the abnormal expression of oncogenes, antioncogenes and cellular adhesion molecules, GSK-3 $\beta$ is suppressed (27), and $\beta$-catenin is accumulated in the cytoplasm without degradation. $\beta$-catenin is then translocated into the nucleus, where it binds to Tcf/Lef and initiates transcription of its target genes, which include c-myc; this results in cellular canceration $(20,28)$. The $\beta$-catenin oncogenic protein is widely expressed in a number of human malignancies (29), including ESCC (30), head and neck squamous cell carcinoma (31-33) and colorectal cancer (34). Additionally, it has been reported that elevated $\beta$-catenin levels promote early neoplastic change through oncogenic signaling within cells $(35,36)$. Therefore, targeting the oncogenic protein $\beta$-catenin may enhance chemotherapy outcome against solid human cancers $(37,38)$. The inactivation of GSK-3 $\beta$ has been reported in numerous cancers with epithelial origin, which include skin, breast, oral, salivary gland, laryngeal and esophageal cancers (39). In accordance with these findings, our study demonstrated that GSK-3 $\beta$ was suppressed in the esophagi of rats in the NMBA control group, while these esophagi also contained the highest levels of $\beta$-catenin. Furthermore, we demonstrated that CPLA induces the inhibition of proliferation in preneoplastic epithelium by modulating the $\beta$-catenin signaling pathway. Our results also demonstrated that CPLA significantly downregulates $\beta$-catenin protein expression and upregulates GSK-3 $\beta$ protein expression, suggesting that CPLA is involved in the inhibition of the Wnt/ $\beta$-catenin pathway in rat esophageal tumorigenesis.

One of the downstream targets of the $\beta$-catenin transcriptional activity involved in cell cycle regulation is c-myc. c-myc, which appeared to have the strongest evidence as an independent predictor of ESCC patient outcome (40), regulates processes involved in numerous aspects of cell fate. Additionally, c-myc is deregulated in several human neoplasias as a result of genetic and epigenetic alterations. The near 'omnipotency' together with a number of regulation levels, makes c-myc an attractive target for tumor intervention therapy (41). In the present study, c-myc was overexpressed in the esophagi of NMBA control rats. CPLA significantly downregulated c-myc expression, suggesting its involvement in inhibiting cell proliferation in rats.

We demonstrated for the first time that CPLA, a novel antitumor active extract from a traditional Chinese medicinal plant, inhibited NMBA-induced rat carcinogenesis via activation of GSK-3 $\beta$ expression and suppression of $\beta$-catenin and c-myc expression. 


\section{Acknowledgements}

This study was supported by the National Natural Science Foundation of China (Grant No. 30772752). We thank the New Drug Research and Development Co., Ltd., North China Pharmaceutical Corporation, China, for their support.

\section{References}

1. Blot WJ and McLaughlin JK: The changing epidemiology of esophageal cancer. Semin Oncol 26: 2-8, 1999.

2. American Cancer Society: Cancer facts and figures, 2005 Atlanta, GA: American Cancer Society, 2005.

3. Zou XN, Chen WQ, Zhang SW, Li LD, Lu FZ and Chen YH: An analysis of esophageal cancer incidence and mortality from 30 cancer registries in China, 1998-2002. Chin Cancer 161: 142-146, 2007.

4. Stoner GD and Gupta A: Etiology and chemoprevention of esophageal squamous cell carcinoma. Carcinogenesis 22 : 1737-1746, 2001.

5. Kakizoe T: Chemoprevention of cancer - focusing on clinical trials. Jpn J Clin Oncol 33: 421-442, 2003.

6. Cragg GM, Grothaus PG and Newman DJ: Impact of natural products on developing new anti-cancer agents. Chem Rev 109: 3012-3043, 2009.

7. Koehn FE and Carter GT: The evolving role of natural products in drug discovery. Nat Rev Drug Discov 4: 206-220, 2005.

8. Mann J: Natural products in cancer chemotherapy: past, present and future. Nat Rev Cancer 2: 143-148, 2002.

9. National Committee of Pharmacopoeia: Pharmacopoeia of the People's Republic of China. Chemical Industry Publishing Company, Beijing, China, pp.181, 2005 (In Chinese).

10. Itokawa H, Xu JP and Takeya K: Studies on chemical constituents of antitumor fraction from Periploca sepium. V. Structures of new pregnane glycosides, periplocosides J, K, F and O. Chem Pharm Bull 36: 4441-4446, 1998.

11. Zhang J, Shan BE and Liu GS: Apoptosis induced by ethyl acetate extract from Cortex periplocae in human breast cancer cell line MCF-7. Tumor 26: 418-421, 2006 (in Chinese).

12. Zhao LM, Shan BE, Ai J, Ren FZ and Lian YS: Effects of periplocin from Cortex periplocae on proliferation of human esophageal carcinoma cells TE-13 and related mechanisms. Tumor 28: 203-206, 2008 (in Chinese).

13. Polakis P: The oncogenic activation of beta-catenin. Curr Opin Genet Dev 9: 15-21, 1999.

14. Waltzer L and Bienz M: The control of beta-catenin and TCF during embryonic development and cancer. Cancer Metastasis Rev 18: 231-246, 1999.

15. Behrens J: Control of beta-catenin signaling in tumor development. Ann NY Acad Sci 910: 21-33, 2000.

16. Lv J, Cao XF, Ji L, Zhu B, Tao L and Wang DD: Association of Wnt1/beta-catenin with clinical pathological characteristics and prognosis of esophageal squamous cell carcinoma. Genet Test Mol Biomarkers 14: 363-369, 2010.

17. Luu HH, Zhang R, Haydon RC, Rayburn E, Kang Q, Si W, Park K, Wang H, Peng Y, Jiang W and He TC: Wnt/beta-catenin signaling pathway as a novel cancer drug target. Curr Cancer Drug Targets 4: 653-671, 2004.

18. Kitagawa M, Hatakeyama S, Shirane M, Matsumoto M, Ishida N, Hattori K, Nakamichi I, Kikuchi A and Nakayama K: An F-box protein, FWD1, mediates ubiquitin-dependent proteolysis of beta-catenin. EMBO J 18: 2401-2410, 1999.

19. Liu C, Li Y, Semenov M, Han C, Baeg GH, Tan Y, Zhang Z, Lin $\mathrm{X}$ and $\mathrm{He} \mathrm{X}$ : Control of beta-catenin phosphorylation/degradation by a dual-kinase mechanism. Cell 108: 837-847, 2002.

20. Nelson WJ and Nusse R: Convergence of Wnt, beta-catenin, and cadherin pathways. Science 303: 1483-1487, 2004.

21. Moon RT, Bowerman B, Boutros M and Perrimon N: The promise and perils of Wnt signaling through beta-catenin. Science 296 1644-1646, 2002.
22. Akiyama T: Wnt/beta-catenin signaling. Cytokine Growth Factor Rev 11: 273-282, 2000.

23. Takahashi-Yanaga F and Sasaguri T: Drug development targeting the glycogen synthase kinase-3beta (GSK-3beta)-mediated signal transduction pathway: inhibitors of the Wnt/beta-catenin signaling pathway as novel anticancer drugs. J Pharmacol Sci 109: 179-183, 2009.

24. Xiang YY, Wang DY, Tanaka M, Igarashi H, Kamo T, Shen Q, Sugimura $\mathrm{H}$ and Kino I: Efficient and specific induction of esophageal tumors in rats by precursors of $\mathrm{N}$-nitrososarcosine ethyl ester. Pathol Int 45: 415-421, 1995.

25. Wang L, Lu A, Liu X, Sang M, Shan B, Meng F, Cao Q and Ji X: The flavonoid Baohuoside-I inhibits cell growth and downregulates survivin and cyclin D1 expression in esophageal carcinoma via $\beta$-catenin-dependent signaling. Oncol Rep 26: 1149-1156, 2011.

26. Osterheld MC, Bian YS, Bosman FT, Benhatter J and Fontolliet C: Beta-catenin expression and its association with prognostic factors in adenocarcinoma developed in Barrett esophagus. Am J Clin Pathol 117: 451-456, 2002.

27. Wu D and Pan W: GSK3: a multifaceted kinase in Wnt signaling. Trends Biochem Sci 35: 161-168, 2010.

28. He TC, Sparks AB, Rago C, Hermeking H, Zawel L, da Costa LT, Morin PJ, Vogelstein B and Kinzler KW: Identification of c-myc as a target of the APC pathway. Science 281: 1509-1512, 1998.

29. Giles RH, van Es JH and Clevers H: Caught up in a Wnt storm: Wnt signaling in cancer. Biochim Biophys Acta 1653: 1-24, 2003.

30. Situ DR, Hu Y, Zhu ZH, Wang J, Long H and Rong TH: Prognostic relevance of $\beta$-catenin expression in T2-3N0M0 esophageal squamous cell carcinoma. World J Gastroenterol 16: 5195-5202, 2010 .

31. Yang F, Zeng Q, Yu G, Li S and Wang CY: Wnt/beta-catenin signaling inhibits death receptor-mediated apoptosis and promotes invasive growth of HNSCC. Cell Signal 18: 679-687, 2006.

32. Goto M, Mitra RS, Liu M, Lee J, Henson BS, Carey T, Bradford C, Prince M, Wang CY, Fearon ER and D'Silva NJ: Rap1 stabilizes beta-catenin and enhances beta-catenin-dependent transcription and invasion in squamous cell carcinoma of the head and neck. Clin Cancer Res 16: 65-76, 2010.

33. Tsai YP, Yang MH, Huang CH, Chang SY, Chen PM, Liu CJ, Teng SC and Wu KJ: Interaction between HSP60 and beta-catenin promotes metastasis.Carcinogenesis 30: 1049-1057, 2009.

34. Morin PJ, Sparks AB, Korinek V, Barker N, Clevers H, Vogelstein B and Kinzler KW: Activation of beta-catenin-Tcf signaling in colon cancer by mutations in beta-catenin or APC. Science 275: 1787-1790, 1997.

35. Dilek FH, Topak N, Tokyol C, Akbulut G and Dilek ON: $\beta$-Catenin and its relation to VEGF and cyclin D1 expression in pT3 rectosigmoid cancers. Turk J Gastroenterol 21: 365-371, 2010.

36. DasGupta R, Kaykas A, Moon RT and Perrimon N: Functional genomic analysis of the Wnt-wingless signaling pathway. Science 308: 826-833, 2005.

37. Saifo MS, Rempinski DR Jr, Rustum YM and Azrak RG: Targeting the oncogenic protein beta-catenin to enhance chemotherapy outcome against solid human cancers. Mol Cancer 9: 310-320, 2010.

38. Paul S and Dey A: Wnt signaling and cancer development: therapeutic implication. Neoplasma 55: 165-176, 2008.

39. Ma C, Wang J, Gao Y, Gao TW, Chen G, Bower KA, Odetallah M, Ding M, Ke Z and Luo J: The role of glycogen synthase kinase 3 beta in the transformation of epidermal cells. Cancer Res 67: 7756-7764, 2007.

40. Wang W, Xue L and Wang P: Prognostic value of $\beta$-catenin, c-myc, and cyclin D1 expressions in patients with esophageal squamous cell carcinoma. Med Oncol 28: 163-169, 2011.

41. Albihn A, Johnsen JI and Henriksson MA: MYC in oncogenesis and as a target for cancer therapies. Adv Cancer Res 107: $163-224,2010$. 